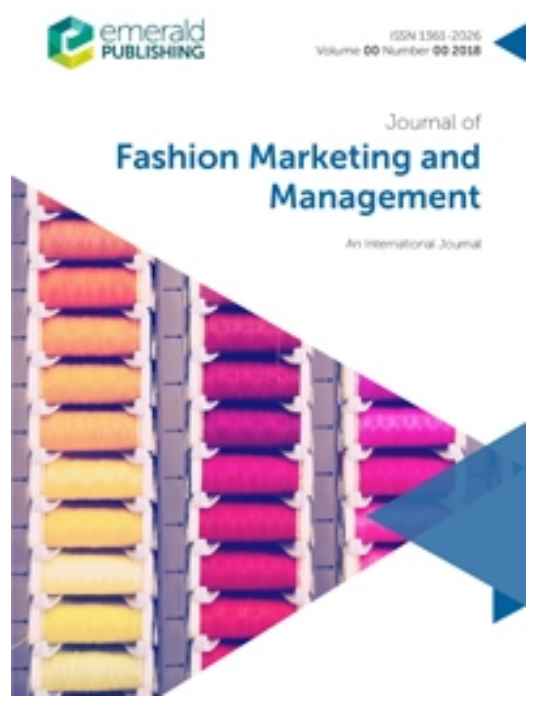

Art to Enhance Consumer Engagement in the Luxury Fashion Domain.

\begin{tabular}{|r|l|}
\hline Journal: & Journal of Fashion Marketing and Management \\
\hline Manuscript ID & JFMM-09-2019-0194.R1 \\
\hline Manuscript Type: & Original Article \\
\hline Keywords: & Luxury fashion brand, Art foundations, Engagement \\
\hline \multicolumn{2}{l}{} \\
\end{tabular}

SCHOLARONE $^{\text {TM }}$

Manuscripts 


\title{
Art to Enhance Consumer Engagement in the Luxury Fashion Domain.
}

\begin{abstract}
Purpose - This paper explores an opportunity for luxury fashion brands to strengthen their engagement with consumers through the arts, and without undermining the exclusivity of the luxury product.

Design/methodology/approach - This paper is based on an interpretive qualitative approach aiming to specifically investigate Fondazione Prada - a contemporary art gallery owned and managed by the fashion brand Prada. Data were collected through semi-structured interviews and a focus group implemented with the 'mystery shopper' technique. Template analysis was used to analyse the data.

Findings - Fondazione Prada has the potential for a deep engagement, but specific lacks of dialogue and interaction need to be addressed. Learning from and sharing values with the public through a two-way peer conversation elicited by contemporary art will benefit both the foundation and the fashion brand, in generating value as the result of a spillover effect. Thus, a significant competitive advantage might be gained.

Originality/value - This paper extends work on Consumer Brand Engagement in physical and non-commercial "brand's places", by evaluating the engagement provided by contemporary art foundations owned by luxury fashion brands. By leveraging the engaging nature of contemporary art, luxury fashion brands could provide an inclusive and engaging experience without undermining the characteristic of exclusivity of the luxury product. Hence, gain a significant competitive advantage for the brand.
\end{abstract}

Keywords Luxury fashion brand, art foundation, engagement

Paper Type Research paper

\section{Introduction}

Luxury and engagement might be considered an oxymoron. The first is generally defined by concepts of social distance, exclusivity, elitism, selection, rarity, expensiveness; while the second is associated with ideas of openness, access, involvement, relationship, acceptance, inclusion, peer relationship. Yet, there might be a point of conjunction between these two opposite concepts in the art world. People strive to live sensorial and intellectual experiences, to connect with other people and the brand. However, in their pursuit of meaning, consumers are starting to question the authenticity and the truthfulness of the many experiences offered by brands (Gilmore and Pine, 2009). Luxury fashion brands should consider this evolution in the conspicuous consumption as an opportunity to evolve their relationship with the consumer. Specifically, by increasing offline opportunities for Consumer Engagement (CE), brands could rethink their relationship with the consumer as a relationship between peers, where transparency in communication might facilitate the consumer contribution in creating the brand (Hatch and Schultz, 2010). By doing so, brands might restore their allure of authenticity and might create a new form of loyalty which will result in strengthening their relationship with the consumer (Dwivedi and McDonald, 2018).

This paper extends work on Consumer Brand Engagement (CBE) by evaluating to what extent luxury fashion brands' art foundations - private art museums/galleries owned by luxury fashion brands - and specifically Fondazione Prada, are providing a deep and authentic CBE by leveraging the engaging nature of contemporary art. Luxury fashion brands' art foundations are here considered as an interesting but neglected opportunity to strengthen the dyadic luxury brand/consumer engagement in a non-commercial and physical environment. Where physical "brand's places" are still considered fundamental to generate important connections with consumers (Alvarez-Milán et al., 2018). On the one hand, physical venues are advantageous to 
strengthen attachment and loyalty towards the brand (Kim and Kim, 2014); on the other hand, these venues can facilitate informing the brand of the customer's preferences and attitude (Amatulli and Guido, 2012). Moreover, by providing a cultural and meaningful experience outside the commercial environment, such as contemporary art exhibitions outside the flagship store, the experience is perceived as more authenticity (Mermiri, 2009); and dedicated cultural space can facilitate inclusive and engaging processes while maintaining the allure of exclusivity and limited access which are characteristic of the luxury product (Fuchs et al., 2010). Hence, the decision to focus this research on Fondazione Prada, a contemporary art gallery owned and managed by Prada, as an opportunity to strengthen CBE in a physical/noncommercial luxury fashion "brand's place".

\section{Literature Review}

\subsection{Contextualising the Term Engagement}

The way the term CE is often employed in marketing studies outlines a one-way relationship with the consumer (Ashley and Tuten, 2015, Gambetti et al., 2012); where the brand has to attract and entertain the consumer more than holding a sincere conversation. When referring to public engagement in the art context instead, although there is no unanimous consensus in defining it (Taylor and Kent, 2014), there is an agreement in considering engagement as a shift from a one-way reception of messages to an active two-way relationship or conversation that might involve a person, or a group of people, in reacting to, generating, and sharing information (Smith and Gallicano, 2015). The term engagement in this deeper connotation, is present in online brands communities' studies (Malhotra et al., 2013), in users' behaviour on social media studies (Paek et al., 2013), in user-generated content on social media studies (Shao, 2009), and in Corporate Social Responsibility (CSR) studies (O'Riordan and Fairbrass, 2014). However, when $\mathrm{CE}$ is referred to as a two-way relationship, the pro-active contribution of the consumer is counterbalanced by the provision of an exceptional service from the brand (Hollebeek, 2011); and providing an exceptional service to consumers who are seeking for meaning, might be perceived as a not sufficient brand's contribution to the relationship anymore (Stephens, 2019). In this scenario of pursuing meaning, by providing a contemporary artistic offer, brands might help to counterbalance the consumer/brand conversation. In particular, considering that public engagement in the art context has a broader scope of generating benefit and well-being (Grossi et al., 2019), brands which are providing artistic offers to the public should consider engagement also from this broader perspective.

Hollebeek's (2011) seminal work frames and measures CBE according to three main dimensions: cognitive engagement, emotional engagement, and behavioural engagement. According to the author, these three dimensions signify the extent to which a consumer is prepared to invest in specific interactions with a brand. In particular, cognitive engagement implies moments of 'immersion' and 'absorption'; emotional engagement implies feelings of 'passion' and 'enthusiasm'; behavioural engagement implies moments of 'activation' and 'interaction' (Hollebeek, 2011). Considering that art is one of the most viable tools to trigger emotions (Belfiore, 2002), facilitate the acquisition of new knowledge (Aguilar et al., 2009), and stimulate interaction (Edmonds et al., 2009), the idea of a luxury brand offering an artistic experience outside the commercial boundaries might ideally fall into Hollebeek's (2011) definition of CBE. Hence, this framework will be used to evaluate Fondazione Prada engagement with the public through its artistic offer, as it will better explain in the methodology section.

When referring to opportunities of brand's engagement, the peer two-way conversation thus mentioned is not often present in offline Consumer Engagement studies (Vivek, 2009), while 
is widely mentioned in those focusing on the online environment (Kaur et al., 2019); and it is even less debated in luxury fashion brands studies regarding offline experiences, where social distance, exclusivity, control, hierarchy, and limited access are still considered fundamental characteristics of the luxury product, and the flagship store (Scharwey, 2017, Kapferer and Bastien, 2012). On the other hand, engagement in the art domain generally refers to a cooperational relationship aiming to solve problems or generate benefits for both the parts involved (Eisner, 2002). Engagement is considered in these studies as a two-way conversation aiming at addressing issues or achieving shared goals, and the conversation operates in a spirit of trustworthiness (Men and Tsai, 2016). By involving the consumer in a peer conversation, the actions and the decisions made in this co-operative spirit might contribute to the social capital of the brand (Burt, 2000). Social capital is here intended as the benefit which derives from "possessing a durable network of more or less institutionalised relationships of mutual acquaintance and recognition" (Bourdieu and Wacquant, 1992).

\subsection{The Importance of Engagement in the Luxury Fashion Domain}

There have been numerous attempts of engagement in the luxury fashion domain, both online and offline. Online through dedicated platform for content co-creation (e.g. Tiffany 'What Makes True Love', and Burberry 'Art of the Trench'); offline through alternative brand experiences (e.g. Tiffany "Blue Box Café", LVMH's open-doors initiative "Les Journees Particulieres", fashion exhibitions in museums such as Dior and Alexander McQueen). Yet, by analysing most of these initiatives aiming to entice consumers towards the brand, one approach which apparently is favoured by many, is that of providing contemporary art exhibitions. Due to this growing trend, there is a need of better evaluating the use of contemporary art in brand's experiences and if these initiatives are contributing to build brand's equity through consumer engagement (Keller, 2001).

Several luxury fashion brands have shown a specific interest in exhibiting contemporary art instore, arguably intrigued by the idea that the proximity of a brand with art allows the brand to be perceived as more luxurious and authentic (Zorloni, 2016, Chailan, 2018). According to Amatulli and Guido (2012), by dedicating part of a brand's flagship store to cultural and artistic experiences and by hiring experts and educated personnel, the association between the brand and the cultural values should be more straightforward in the customers' minds. Nevertheless, the logic of the market which are permeating the modern society are also undermining the authenticity of the artistic offer; thus, the store is no longer the most effective place to provide these experiences (Kozinets, 2002). Furthermore, if the art investment is not coherent with the brand identity, there is the risk of deteriorating the situation and of losing credibility (Jelinek, 2018). Engagement has to be considered pivotal, in the spirit of creating an experience alongside with the consumers which might be perceived as more authentic (Dessart et al., 2015).

This paper is focusing in particular on luxury fashion brands' art foundations, them being a non-commercial art-related "brand's place". In this research, art is an intertwined domain with luxury, thus it is important to explore the concept of Engagement also in the art context. In this context, public engagement is "the involvement, participation, and interaction between one 'producer' of art and one (or a group of) 'receiver/s' of art in a two-way conversation for coproducing benefits and/or improving a situation" (Grassi et al., 2018). By taking this into account, engagement as a two-way conversation to co-produce benefits becomes particularly relevant when related to the luxury fashion domain. Historically, the luxury brand's relationship with the consumer has been based on the need for the brand of controlling how it is presented to the public and the way it is experienced (Doyle et al., 2008). Flagship stores 
have been the most utilised channel for brands to exercise a level of control which would have been difficult to achieve through other channels (Moore et al., 2004). However, the conspicuous consumption is evolving by moving away from merely experiencing commodities, towards experiencing culture and well-being (Bronner and de Hoog, 2018). This evolution is leading consumers towards experiencing the brand outside the conventional "brand's places" such as the flagship store, and as a consequence, the level of control exercised by the brand in orienting the consumer's experience will be harder to achieve.

CBE develops when consumers establish a deep emotional bond with the brand (Vivek et al., 2012). Through CBE, the consumers' role is enhanced by being involved in the process of value co-creation (Dessart et al., 2015). Moreover, CBE transforms the consumer into a fan of the brand, due to the strong relationships created, which may bring him/her to energetically promote the brand and its products (Sashi, 2012). By increasing opportunities of engagement in non-commercial physical "brand's places", luxury fashion brands could benefit from the positive effect generated by moments of interaction, feelings of enthusiasm and inclusivity, and the perceived authenticity of the experience, without the risk of undermining the allure of exclusivity which characterised their product; thus, gaining a significant competitive advantage (Gilmore and Pine, 2009). This paper aims to evaluate if luxury fashion brands' art foundations, and specifically Fondazione Prada, are providing a deep and authentic Consumer Brand Engagement by leveraging the engaging nature of contemporary art.

\section{Research Method}

This research is based on an interpretive qualitative approach, as it was considered the most appropriate to allow a rich in-depth insight of a contemporary phenomenon and the way people are experiencing it (Carson et al., 2001). The qualitative approach has been extensively used in the marketing context, especially in brand experiences researches (Hollenbeck et al., 2008); and in Consumer Engagement studies, where a qualitative approach appears particularly suitable for investigating nuances of people's feelings and reactions towards an experience (Gómez-Suárez et al., 2016). The philosophy underpinning this study considers that any human being is creating and experiencing a specific social world any time different from other people's world. Different backgrounds, beliefs, circumstances, and times are shaping different realities, and any person is giving a specific and distinct meaning to this reality (Saunders et al., 2016). The methods applied in this research are considering any single person as a unique contributor to the evaluation of the kinds of experiences that Prada is providing through its foundation.

\subsection{Why Fondazione PRADA?}

Secondary research allowed to identify specific elements which characterise art foundations owned by luxury fashion brands. Of all these elements, four were identified as the most recurrent and were used to select the case for this study. First, the nature of the luxury brands' project, and private foundations (i.e. permanently-established physical and non-physical entities with an open-ended operation and perhaps vague purpose) were preferred because of their ongoing operation, higher profile, and the consequent, presumably more significant financial and human capital employed by the brands (Zorloni, 2016). Second, the type of art promoted, and brands sponsoring contemporary art in all its forms were preferred because considered more complex and structured cases to investigate, than those sponsoring one single art form. Third, the presence of educational programmes, deemed important because of the powerful potential of educational activities as tools for engagement (Kay, 2000). Last, the venue, and those foundations with dedicated venues were selected due to the possibility for people to attach meaning to places, thus facilitate engagement (Pollock and Paddison, 2014). 
Out of the eight luxury fashion brands' art foundations analysed, only two were showing all these elements, and of these two, Fondazione Prada was selected for this paper.

\subsection{Data Collection}

Data were collected through two methods: semi-structured interviews, and a focus group. Four semi-structured in-depth interviews were conducted with experts in public engagement, and professionals from the fashion industry; one semi-structured in-depth interview was conducted with one product manager and one curator of Fondazione Prada. The sampling was a convenient sampling (Hair et al., 2016). Experts were selected from a list of possible clusters in the UK professional networks, such as fashion magazines, museums, art galleries, members of the National Co-ordinating Centre for Public Engagement, the British Fashion Council, fashion bloggers. The use of in-depth interviews is considered very effective to investigate people's experiences and opinions (Taube and Warnaby, 2017). The interviews with experts were focusing on their opinion regarding three main themes: luxury fashion brand, public engagement, and luxury fashion brands' art foundations. The interview with Fondazione Prada associates was focusing on understanding the organisational structure of the foundation, the relationship between the foundation and the brand, the kinds of activities which the foundation organises.

The focus group involved five participants selected through convenient sampling. The focus group showed homogeneity with a sufficient variation (Krueger, 1994) to allow differentiated opinions and facilitate a dynamic and inclusive discussion (Bloor et al., 2001). The conversation was based on the participants' visit to Fondazione Prada and it was organised four months after their visits. The 'mystery shopper' tactic was applied to the participants' visit to evaluate the way they experienced the foundation (Jacob et al., 2016). An email was sent with an attached document containing flexible guidelines to ease the visit and the conversation afterwards, and a cover letter explaining the aim of the exercise in a consistent way. The discussion mainly involved the participants' description of their experience with specific questions related to accessing information, the presence of activities such as moments of interactivity or conversation, and a comparison to other museums visited. To achieve validity, a follow-up email was sent to all participants six months after the focus group, asking for verification of the interpretation of the data.

\subsection{Data Analysis}

The interviews and the focus group were audio-recorded and transcribed verbatim for analysis. All participants were associated with a code to guarantee anonymity. Table 1 shows relevant details regarding the participants of this research.

\section{[Table 1 here]}

All data were coded line-by-line through NVivo, including open and axial coding (Strauss and Corbin, 1998) and were analysed by using Template Analysis (King and Brooks, 2017). Template Analysis is a typology of thematic analysis characterised by the development of a coding template typically created on the base of a small subset of data. The template is then applied to all the other data (Brooks et al., 2015). Template Analysis is a flexible approach with no coding levels suggested in advance, however, it allows the use of "a priori" themes derived from the literature review (Brooks et al., 2015). Template Analysis uses an iterative and adaptive approach towards the emergence of new themes and issues. The first set of data was coded and allowed the development of the first prototype of the template, which then was refined and integrated step by step when applied to the further set of coded data. Hollebeek's 
(2011) framework to evaluate CBE was applied and themes were linked to the three main dimensions that the author used to define CBE, and which were described in section 2.1. The main focus of the analysis was on the different experiences lived by participants while visiting the foundations, with specific attention on elements of engagement. Experts opinions served to enhance the understanding of the context of engagement, luxury fashion brands, and cultural institutions; while the insight from Fondazione Prada associates helped in comparing their offer to the participants' perception of the foundation. In particular, words such as 'interaction', 'access', and 'inclusion' were identified. From this, five main themes emerged: access, interaction, sharing, knowledge acquisition, inclusivity. These themes were then linked back to Hollebeek's (2011) framework of cognitive, emotional, and behavioural engagement aiming to evaluate the level of CBE provided by Fondazione Prada. In the following section, findings and discussion are presented according to the three dimensions of the CBE framework, and the themes emerged during the analysis.

\section{Findings \& Discussion.}

\subsection{Behavioural engagement}

\subsubsection{Access}

The accessibility of the place is one of the first aspects to consider in evaluating the level of engagement of a museum/art gallery. Scholars sustain that limited access - physical, of information, or cultural - might decrease visits to cultural institutions (Shein et al., 2015). By limiting the opportunity to access, the first step towards engagement is also limited.

Just when you talk about public and museums, it is with a view to engage as many people as possible in the widest possible definition [...] we're open to anyone the public can be anyone. [...] you talk about public engagement as bringing people into contact with what you do who might have no interest and you're working quite hard to make them interested. (E1)

Fondazione Prada is located in a part of the city of Milan which is not central. They also own a second space dedicated only photographic exhibitions in the heart of Milan (Galleria Vittorio Emanuele). During the interview with the Fondazione's associates, it emerged that they consider this second venue as a possible catalyst for tourists towards the main buildings of the foundation. Their idea is that by visiting the Osservatorio, people might decide to reach also the main venue, showing to acknowledging the importance of giving ease access to Fondazione Prada. However, during the focus group, it emerged that all participants faced similar difficulties to reach the foundation. Moreover, participants complained of feeling lost once inside the gate, with no sign showing the location of the ticket office, or the reception. 'Confusion' and 'frustration' were the most frequent terms used during this part of the conversation.

The idea of concealing clear and immediate indications on how to navigate the foundation is made on purpose and to challenge the visitor. Yet, according to the interview with the Fondazione's associates, confusion and frustration are feelings which they would like to avoid generating.

First of all, the public gets lost. That is something which you should absolutely never do. You should take (the public) by hand [...] and never make him(/her) feel lost. So, what does Fondazione Prada? It says 'listen, visitor, contemporary art, the world, the fashion industry, they are not all sunshine and rainbow. [...] You public need to make an effort and look around, read the space in which you are, and decide to talk to someone. (P2) 
This could be a very clever idea to engage the public with something different, but it might also be difficult to understand and appreciate by people less oriented towards challenges, or people who do not see in the incapability of finding the toilet as a challenge.

I jotted on the guidance paper that I wasn't able to get in. I've asked three different people 'go there', 'go that way', 'go over there' and in the end, I was in the bar (not the ticket office). (FG2)

Any time you get out of a building you don't know where you are or where to go... Any time I got out in the main square, I said: 'and know what?' (FG1)

To make it feasible, this idea of challenge should somehow be introduced to the public. As a way to transform this challenge from frustration to fun, it might be worth considering storytelling, narrative, or gaming techniques which have been proven very effective for engaging with visitors (Danks et al., 2007). At the moment, the foundation and the public are apparently speaking a different language.

\subsubsection{Interaction}

With regard to 'interaction, the participants to the focus group extensively discussed the foundation's experience compared to other related experiences they have consumed. The rules of hospitality applied by the foundations are not different from those of other museums. Yet, none of the participants identified something worth mentioning with regard to specific interactive moments. One person noted that the foundation organises thematic activities for children - Accademia dei Bambini -, but nothing similar is offered to the adults.

Accademia dei Bambini decides quite a broad theme every trimester, that could be: the sea and the waves, the numbers and maths, robots... and developed something special for the children through the involvement of an expert in that specific sector. These events are free; you just need to book. Parents have to stay with the little ones and leave the old ones, but usually, they all love to stay. (P2)

People might receive more positively, and remember longer, experiences which are impressive and different There are no spaces to leave comments, there is no mobile application (app), there is no piece of art which required a level of interactivity from the public. All the participants clearly said that they would have appreciated something more interactive, and provided as an example the level of interactivity which is present in science museums. Science museums are generally offering moments of learning developed around complex concepts by utilising different and engaging strategies; and participants appeared much more impressed and enthusiastic to discuss those experiences than other experiences.

At the heart of engagement, we're looking at social, so looking for new connections, finding new ways to interact with new people, developing yourself. (E3)

There are different ways to involve the public in a conversation, and this paper distinguishes public engagement activities in two main categories, as emerged from interviews with experts: "Strong-touch activities", and "Light-touch activities".

For example, I report my experience. In Oslo, at the national museum, there was a room where anyone could draw a sculpture, and there were a lot of people in the room. Then, 
all the drawings were hung on the wall, and also those were becoming a sort of art. I've spent at least an hour in that room; the idea impressed me... I would have appreciated something like that (in Fondazione Prada). (FG2)

These kinds of "Light-touch activities" are organised by many museums, and are generally very successful in engaging the public in conversations (Deeth, 2012). When referring to what this paper calls "Strong-touch activities" instead, the level of commitment required to both the public and the institution is higher.

I worked with a small group of men who lived in a care home. So, they would work with an artist, a curatorial team and a conservation team and look at works in the (our) collection, have conversations about how they felt about that work and the audience that would appeal to. [...] It was seen by over 50,000 people through the gallery. [...] A lot of the men thought that a gallery would be somewhere you would go as a family or with your children (now they've changed their minds). (E3)

A more focused approach in providing learning moments, not only dedicated to schools and children, might be something the foundation could consider to encourage a two-way conversation. Such level of interaction could help to transform the experience at the foundation in a memorable experience, thus, strengthening a peer relationship with the brand without undermining exclusivity and limited access which characterise the product (Fuchs et al., 2010).

\subsubsection{Sharing}

Sharing experiences on social media is considered a form of electronic world-of-mouth (EWOM), which is believed more authentic than other forms of corporate-driven advertisement (Subramanian, 2018). It is also a useful scale for measuring people engagement (Hausmann and Poellmann, 2016).

I guess that (social media) is public engagement in the truest sense of the word because I have access, it's the brand giving me access to this closed-off world. (E2)

All the participants voluntarily took a few pictures and videos of the visit, mainly of the Fondazione's building. FG3 and FG5 shared a couple of pictures on social media, choosing Instagram as platform. FG1 explained that, differently than in this visit, during her first visit to the Fondazione, there was a particular piece of art, perfect for her Instagram feeds, composed of 8 ceiling-high bronze statues, each one dressed with a single fashion item ("The Giacometti Variation" - John Baldessari).

(the installation of statues) was definitely 'Instagrammable'. (FG1)

A star-architect designed building is an excellent way to facilitate EWOM, but also some small curiosities, might influence peoples' decisions to share their experiences online. Examples are FG1 bronze statues, or a thematic pinball which FG4 found in the Fondazione café and representing a Wes Anderson movie. Providing specific opportunities to encourage social media interactions and sharing is an effective way to create a unique experience, especially if implemented with storytelling, narrative, or gaming techniques (as explained in Theme 1). People are increasingly obsessed with sharing every aspect of their life. Moreover, leisure activities are increasingly chosen based on the symbolism and the meaning attached to them, and on the effect which is generated on other people's perceptions (Colton, 1987). There is a 
sort of hidden rule among people that an experience not shared is an experience not lived, which the social influence theory easily justify (Venkatesh et al., 2002). People shape part of their behaving by believing that their personal network wants them to perform that particular behaviour (Kang and Schuett, 2013). In this, social media are magnifying this behaving and are reshaping the consumer culture (Schmitt and Zarantonello, 2013).

\subsection{Cognitive Engagement}

\subsubsection{Knowledge Acquisition.}

Public engagement starts with the programme and the educational work. (E1)

Facilitating the acquisition of new knowledge is one of the key points of public engagement in the art context (Lewenstein, 2011), and cognitive engagement is key to CBE evaluation (Hollebeek, 2011).

During the interview with the Fondazione's associates, emerged that they have approximately 100 attendants who work at the foundation, selected according to different specialisations, in art, history, architecture, or geography. All the attendants are trained directly by Fondazione Prada to ensure a high level of preparation, and consistency in the quality of the service provided.

During the focus group emerged that most of the participants were unaware of the role of attendants. They have the idea that employees present in the rooms were mainly concerned with security. The researcher was aware of this peculiarity as emerged from interviews with experts, and for this reason, asked specifically the participants to look for information by asking the attendants. Participants admitted to 'fear' asking for explanations because of their perception of the art world as an elitist world. They felt that by asking information they were admitting a level of ignorance and inadequacy. This might explain the encouragement of one of the attendants towards a participant to ask her or her colleagues for more information. The participant felt as she was implying that people are not used to approaching them. This might be something that the foundation could address to encourage people in engaging in a dialogue.

The participants were expecting walls providing a written explanation regarding a room, as for in other museums. In particular, because of the type of art displayed by Fondazione Prada, which they considered challenging and in need of explanations. The lack of details provided by brochures exacerbated participants' need for understanding. This lack of information is sometimes justified by the attendants as a lack of explanation offered by the artist, which brings the foundation to avoid speculations regarding meanings, and to allow a free interpretation to the public. However, some participants highlighted that explanations of the historical context, or the artist's life, might facilitate the public's interpretation. Finally, participants discussed the idea of a mobile app to facilitate the visit of the foundation. They discussed that Fondazione and the public could benefit from this app, and that some specific interactive content would increase the quality of the experience at Fondazione Prada. For instance, FG4, a frequent visitor of museums of contemporary art, said that the kind of art displayed by the foundation felt more difficult to understand.

At the MoMa there are different forms of art, but even the most modern or most contemporary is easier to understand in comparison to the art in the foundation. [...] I'd 
like to visit the foundation again, but I'd look for more information about the exhibition before going [...] Well, there (at MoMa), there is Andy Warhol, the pop art, you know... there is no need... you don't need a guide to tell you what 'the tin' represents [...] (in other museums) if I have to ask for explanation it might happen once in all the visit... in the foundation, you'd need explanations for all. (FG4)

However, in the end, all of the participants showed a level of knowledge acquisition due in part to the visit, and in part to the conversation occurred during the focus group. As previously said, understanding a piece of art due to a clear explanation had a major impact on the participants' experience. Yet, this conversation regarding the arts should be two-way and the foundation should also be a learning subject in the conversation, not only the public.

I think it is really exciting to be able to be inclusive and invite different audiences in for different types of discussions and I think there is tremendous learning that can take place for everybody involved in that [...] stimulate debate. [...] It is important to engage in that debate more than celebrating the established values. (E4)

Discussing the experiences with the group, and receiving quick but detailed explanations were identified by the participants as significant moments of engagement. This sustains the idea that by implementing the foundations' strategies with higher involvement activities and moments of interaction, might increase the level of engagement offered.

[...] (we are aiming to provide) an experience useful to personal growth. You can't force utility, and you can't even explain it (utility)... you make it an experience. So, if it is not your experience, is not useful. This is what we do. (P2)

The Fondazione is showing some clear attempts in providing a special experience through high-quality learning, and a clear intent to engage with the public. However, it appears that the foundation is still feeling in a dominant position of control compared to the public, the position of provider of knowledge. This is preventing the Fondazione to engage in learning experiences which might benefit both the foundation and its programme, and the brand in a spirit of cocreation (Pongsakornrungsilp and Schroeder, 2011). Learning from and sharing values with the public could benefit the generation of brand value as the result of a spillover effect (Balachander and Ghose, 2003).

\subsection{Emotional Engagement 4.3.1 Inclusivity}

Participants were asked to reflect on their expectations before and after visiting the Fondazione. The majority admitted that, before the visit, they were expecting a fashion exhibition, or something dedicated to the brand and its history. Yet, discovering that this was not the case, left them with the curiosity to know why a fashion brand decides to invest many resources in the arts. People automatically associate the foundation with the brand because of the shared name, thus this confusion. Yet, once aware of its real nature, participants positively commented the fact that an exclusive and luxury fashion brand has decided to invest for helping people to access this world. Especially when people use to associate contemporary art with the idea of a niche and elitist world hard to access (Fisher, 2001, Bell, 1974). Arguably, there is a lack in communicating the Fondazione outside its inner circle, if there is still confusion about its existence and its nature. 
(Prada delivers) fashion collections which are inspired by some complex concept... obviously, there is a huge coherence with the foundation's activity [...] (the foundation is a) strengthening of some fundamental values of the brand which are coherent with our (the foundation) activities. [...] But for them (Miuccia Prada and Patrizio Bertelli) art is a passion, fashion is a job. (P1)

Prada should abandon the idea of keeping the two realities dissociated. Instead, the brand should exploit more its renown promotional skills to communicate the foundation and its scope, with no fear of intertwining these two realities, but finding interesting and innovative ways to deliver the message and the values they share.

Encouraging reflections on an overall experience afterwards is a powerful tool to evaluate engagement and influences that this experience has generated (Soren, 2009). As a reply to a direct question, participants felt that generally, the experience left them indifferent. Yet, continuing the conversation, they showed to remember many details, especially of the explanations gathered, long after their visit (and even more as in the follow-up email). Some reported that having discussed the experience and exchanged opinions with peers reinforced these memories and also the experience itself. This suggests that some dedicated moments for dialogue could make the experience at the Fondazione more significant, and the effect more durable. Another aspect, as previously mentioned, which participants deemed significant in influencing their experience was the opportunity to understand a piece of contemporary art due to the explanation received. By understanding the art exhibited, they felt included in a world which they normally considered alien to them. Encouraging dialogue around pieces of art/artists helps in opening people towards contemporary art, generally considered difficult and for a few. As engagement activities organised by science museums erase feelings of inadequacy for technology and science, even if never studied before; specific engagement activities in the art context, help to provide the same benefit towards artworks.

Dialogue and conversation around something considered exclusive (contemporary art) and provided by an exclusive brand, apparently helped in generating a shared feeling of inclusivity, of being part of something. Interpersonal exchange and conversations were pivotal elements identified as triggers of a certain level of engagement with the art, as highlighted by the participants while discussing new knowledge, and inclusivity.

\section{Conclusions}

Hollebeek's (2011) framework was utilised in this paper to evaluate the extent of engagement provided by Prada through the use of contemporary art in its Fondazione Prada. Behavioural engagement was discussed through themes of 'access', 'interaction', and 'sharing'. For what concerns 'access', the lack of indications on how to navigate the foundation could become a powerful way to deepen behavioural engagement. Fondazione Prada would need to implement techniques of storytelling, narrative, or gaming, very effective for engaging with visitors (Danks et al., 2007), to transform what is now considered frustrating in a game which would also create specific moments of interaction. Moments which the participants recognised to be lacking and would have appreciated to find more. Moreover, interpersonal exchange and moments of conversation during the visit would have helped to deepen the level of interaction, as it happened during the focus group. Finally, the use of digital tools and the organisation of 'sharable' moments, would have also improved the interactivity inside Fondazione Prada. 
Cognitive engagement was discussed through the theme of 'knowledge acquisition', having considered contemporary art a particularly powerful tool to facilitate this kind of engagement. From the results emerged that the foundation might want to consider implementing easiest ways for the public to gain information and be involved in a dialogue with the attendants. Generally, participants felt afraid of asking for information because worried to show a level of inadequacy towards the artworks; and public engagement activities normally help in bridging this gap.

Finally, the simple fact of understanding a form of art generally considered difficult and alien, made the participants feel part of something, included. However, the participants were not lovers of the brand, or particularly inclined towards this kind of art, and this might have resulted in a weaker emotional engagement (considered a limitation of this research). Yet, positive reactions were registered during all the experience, and this leads to considering that by targeting people passionate of the brand or the art, the level of emotional engagement provided by Fondazione Prada could be very deep.

To conclude, in the luxury environment where limited access, social distance, and exclusivity are fundamental to preserve the perceived value of the luxury product, art foundations such as Fondazione Prada might be pivotal to engage with the consumer without undermining the luxury product; to strengthen the relationship between the brand and the consumer; and to gain significant competitive advantage.

Limitations of Hollebeek's (2011) framework apply to this study; and as a limitation could be considered the number of participants involved in this research. Further research might consider developing this idea further, by extending the research also to a larger number of participants, and by applying different evaluation frameworks.

\section{References}

AGUILAR, J., BEDAU, D. \& ANTHONY, C. 2009. Growing Emotional Intelligence through Community-Based Arts. Reclaiming Children and Youth, 18, 3.

ALVAREZ-MILÁN, A., FELIX, R., RAUSCHNABEL, P. A. \& HINSCH, C. 2018. Strategic customer engagement marketing: A decision making framework. Journal of Business Research, 92, 61-70.

AMATULLI, C. \& GUIDO, G. 2012. Externalised vs. internalised consumption of luxury goods: propositions and implications for luxury retail marketing. The International Review of Retail, Distribution and Consumer Research, 22, 189-207.

ASHLEY, C. \& TUTEN, T. 2015. Creative strategies in social media marketing: An exploratory study of branded social content and consumer engagement. Psychology \& Marketing, 32, 15-27.

BALACHANDER, S. \& GHOSE, S. 2003. Reciprocal spillover effects: A strategic benefit of brand extensions. Journal of Marketing, 67, 4-13.

BELFIORE, E. 2002. Art as a means of alleviating social exclusion: Does it really work? A critique of instrumental cultural policies and social impact studies in the UK. International Journal of Cultural Policy, 8, 91-106.

BELL, Q. 1974. Art and the Elite. Critical Inquiry, 1, 33-46.

BLOOR, M., FRANKLAND, J., THOMAS, M. \& ROBSON, K. 2001. Focus groups in social research, London, SAGE.

BOURDIEU, P. \& WACQUANT, L. J. 1992. An invitation to reflexive sociology, University of Chicago press. 
BRONNER, F. \& DE HOOG, R. 2018. Comparing conspicuous consumption across different experiential products: Culture and leisure. International Journal of Market Research, 1470785318799898.

BROOKS, J., MCCLUSKEY, S., TURLEY, E. \& KING, N. 2015. The utility of template analysis in qualitative psychology research. Qualitative Research in Psychology, 2, 202-222.

BURT, R. S. 2000. The contingent value of social capital. Knowledge and social capital. Elsevier.

CARSON, D., GILMORE, A., PERRY, C. \& GRONHAUG, K. 2001. Qualitative marketing research, Sage.

CHAILAN, C. 2018. Art as a means to recreate luxury brands' rarity and value. Journal of Business Research, 85, 414-423.

COLTON, C. W. 1987. Leisure, recreation, tourism: A symbolic interactionism view. Annals of Tourism Research, 14, 345-360.

DANKS, M., GOODCHILD, M., RODRIGUEZ-ECHAVARRIA, K., ARNOLD, D. B. \& GRIFFITHS, R. Interactive storytelling and gaming environments for museums: The interactive storytelling exhibition project. International Conference on Technologies for E-Learning and Digital Entertainment, 2007. Springer, 104-115.

DEETH, J. 2012. Engaging Strangeness in the Art Museum: an audience development strategy. museum and society, 10, 1-14.

DESSART, L., VELOUTSOU, C. \& MORGAN-THOMAS, A. 2015. Consumer engagement in online brand communities: a social media perspective. Journal of Product \& Brand Management, 24, 28-42.

DOYLE, S. A., MOORE, C. M., DOHERTY, A. M. \& HAMILTON, M. 2008. Brand context and control: the role of the flagship store in B\&B Italia. International Journal of Retail \& Distribution Management, 36, 551-563.

DWIVEDI, A. \& MCDONALD, R. 2018. Building brand authenticity in fast-moving consumer goods via consumer perceptions of brand marketing communications. European Journal of Marketing, 52.

EDMONDS, E., BILDA, Z. \& MULLER, L. 2009. Artist, evaluator and curator: Three viewpoints on interactive art, evaluation and audience experience. Digital Creativity, 20, 141-151.

EISNER, E. W. 2002. The arts and the creation of mind, Yale University Press.

FISHER, J. A. 2001. High art versus low art. Routledge Companion to Aesthetics. London: Routledge, 409-421.

FUCHS, C., PRANDELLI, E. \& SCHREIER, M. 2010. The psychological effects of empowerment strategies on consumers' product demand. Journal of Marketing, 74, 6579.

GAMBETTI, R. C., GRAFFIGNA, G. \& BIRAGHI, S. 2012. The grounded theory approach to consumer-brand engagement. International Journal of Market Research, 54, 659687.

GILMORE, J. \& PINE, J. 2009. Using art to render authenticity in business. In: MERMIRI, T. (ed.) Beyond experience:

culture, consumer \& brand. London: Arts\&Business.

GRASSI, A., SWINDELLS, S. \& WIGLEY, S. 2018. The Art Foundations of Luxury Fashion Brands: An Exploratory Investigation. Engaging with Fashion. Brill Rodopi.

GROSSI, E., BLESSI, G. T. \& SACCO, P. L. 2019. Magic moments: Determinants of stress relief and subjective wellbeing from visiting a cultural heritage site. Culture, Medicine, and Psychiatry, 43, 4-24. 
GÓMEZ-SUÁREZ, M., BENITO, L. E. A. \& CAMPO, S. 2016. Exploring the link between brand love and engagement through a qualitative approach. International Journal of Business Environment, 8, 367-384.

HAIR, J. F., CELSI, M., MONEY, A. H., SAMOUEL, P. \& PAGE, M. 2016. Essentials of business research methods, New York, Routledge.

HATCH, M. J. \& SCHULTZ, M. 2010. Toward a theory of brand co-creation with implications for brand governance. Journal of Brand Management, 17, 590-604.

HAUSMANN, A. \& POELLMANN, L. 2016. eWOM in the performing arts: exploratory insights for the marketing of theaters. Arts and the Market, 6, 111-123.

HOLLEBEEK, L. 2011. Exploring customer brand engagement: definition and themes. Journal of strategic Marketing, 19, 555-573.

HOLLENBECK, C. R., PETERS, C. \& ZINKHAN, G. M. 2008. Retail spectacles and brand meaning: Insights from a brand museum case study. Journal of Retailing, 84, 334-353.

JACOB, S., SCHIFFINO, N. \& BIARD, B. 2016. The mystery shopper: A tool to measure public service delivery? International Review of Administrative Sciences, 84, 164-184.

JELINEK, J.-S. 2018. Art as strategic branding tool for luxury brands. Journal of Product \& Brand Management, 27, 294-307.

KANG, M. \& SCHUETT, M. A. 2013. Determinants of sharing travel experiences in social media. Journal of Travel \& Tourism Marketing, 30, 93-107.

KAPFERER, J.-N. \& BASTIEN, V. 2012. The luxury strategy: Break the rules of marketing to build luxury brands, Kogan page publishers.

KAUR, H., PARUTHI, M., ISLAM, J. \& HOLLEBEEK, L. D. 2019. The Role of Brand Community Identification and Reward on Consumer Brand Engagement and Brand Loyalty in Virtual Brand Communities. Telematics and Informatics, 101321.

KAY, A. 2000. Art and community development: The role the arts have in regenerating communities. Community Development Journal, 35, 414-424.

KELLER, K. 2001. Building customer-based brand equity: A blueprint for creating strong brands.

KIM, J. \& KIM, J.-E. 2014. Making customer engagement fun. Journal of Fashion Marketing and Management, 18, 133-144.

KING, N. \& BROOKS, J. M. 2017. Template analysis for business and management students, London, SAGE.

KOZINETS, R. 2002. Can consumers escape the market? Emancipatory illuminations from burning man. Journal of Consumer research, 29, 20-38.

KRUEGER, R. A. 1994. Focus groups: A practical guide for applied research, Thousand Oaks, CA, SAGE Publications.

LEWENSTEIN, B. V. 2011. Experimenting with engagement. Science and Engineering Ethics, 17, 817-821.

MALHOTRA, A., MALHOTRA, C. K. \& SEE, A. 2013. How to create brand engagement on Facebook. MIT Sloan Management Review, 54, 18.

MEN, L. R. \& TSAI, W.-H. S. 2016. Public engagement with CEOs on social media: Motivations and relational outcomes. Public Relations Review, 42, 932-942.

MERMIRI, T. 2009. The transformation economy. In: MERMIRI, T. (ed.) Beyond experience: Culture, consumer \& brand.: Arts\&Business.

MOORE, C. M., BIRTWISTLE, G. \& BURT, S. 2004. Channel power, conflict and conflict resolution in international fashion retailing. European Journal of Marketing, 38, 749769.

O'RIORDAN, L. \& FAIRBRASS, J. 2014. Managing CSR stakeholder engagement: A new conceptual framework. Journal of Business Ethics, 125, 121-145. 
PAEK, H.-J., HOVE, T., JUNG, Y. \& COLE, R. T. 2013. Engagement across three social media platforms: An exploratory study of a cause-related PR campaign. Public Relations Review, 39, 526-533.

POLLOCK, V. L. \& PADDISON, R. 2014. On place-making, participation and public art: The Gorbals, Glasgow. Journal of Urbanism: International Research on Placemaking and Urban Sustainability, 7, 85-105.

PONGSAKORNRUNGSILP, S. \& SCHROEDER, J. E. 2011. Understanding value cocreation in a co-consuming brand community. Marketing Theory, 11, 303-324.

SASHI, C. M. 2012. Customer engagement, buyer-seller relationships, and social media. Management Decision, 50, 253-272.

SAUNDERS, M., LEWIS, P. \& THORNHILL, A. 2016. Research methods for business students, Harlow, Pearson Education.

SCHARWEY, A. Social distance in customer-service employee encounters: a luxury vs. nonluxury comparison. International Marketing Trend Conference - Luxury Industries, 2017 London.

SCHMITT, B. \& ZARANTONELLO, L. 2013. Consumer Experience and Experiential Marketing: A Critical Review. In: MALHOTRA, N. K. (ed.) Review of Marketing Research. Emerald Group Publishing Limited.

SHAO, G. 2009. Understanding the appeal of user-generated media: a uses and gratification perspective. Internet Research, 19, 7-25.

SHEIN, P. P., LI, Y.-Y. \& HUANG, T.-C. 2015. The four cultures: Public engagement with science only, art only, neither, or both museums. Public Understanding of Science, 24, 943.

SMITH, B. G. \& GALLICANO, T. D. 2015. Terms of engagement: Analyzing public engagement with organizations through social media. Computers in Human Behavior, $53,82-90$.

SOREN, B. J. 2009. Museum experiences that change visitors. Museum Management and Curatorship, 24, 233-251.

STEPHENS, D. 2019. In Brands We Trust: Why Companies Are the New Communities. Business of Fashion.

STRAUSS, A. \& CORBIN, J. 1998. Basics of qualitative research techniques, Sage publications Thousand Oaks, CA.

SUBRAMANIAN, K. 2018. Social Media and the Word of Mouth Publicity. Science, 3, 95100.

TAUBE, J. \& WARNABY, G. 2017. How brand interaction in pop-up shops influences consumers' perceptions of luxury fashion retailers. Journal of Fashion Marketing and Management: An International Journal, 21, 385-399.

TAYLOR, M. \& KENT, M. L. 2014. Dialogic engagement: Clarifying foundational concepts. Journal of Public Relations Research, 26, 384-398.

VENKATESH, V., SPEIER, C. \& MORRIS, M. G. 2002. User acceptance enablers in individual decision making about technology: Toward an integrated model. Decision sciences, 33, 297-316.

VIVEK, S. D. 2009. A scale of consumer engagement. University of Alabama Libraries.

VIVEK, S. D., BEATTY, S. E. \& MORGAN, R. M. 2012. Customer engagement: Exploring customer relationships beyond purchase. Journal of marketing theory and practice, 20, 122-146.

ZORLONI, A. 2016. Art Wealth Management : Managing Private Art Collections, Cham, Springer. 


\begin{tabular}{|l|l|c|l|}
\hline CODE & ROLE/CONTRIBUTION & GENDER & JOB TITLE/ROLE \\
\hline E1 & Expert in Public Engagement & $\mathrm{F}$ & Director of a Museum in London \\
\hline E2 & $\begin{array}{l}\text { Expert in Public Engagement } \\
\text { and Luxury Brands }\end{array}$ & $\mathrm{M}$ & Manager for the British Fashion Council \\
\hline E3 & Expert in Public Engagement & $\mathrm{M}$ & $\begin{array}{l}\text { Public Engagement Manager in an Art } \\
\text { Gallery in Manchester }\end{array}$ \\
\hline E4 & $\begin{array}{l}\text { Expert in Public Engagement } \\
\text { and Luxury Brands }\end{array}$ & $\mathrm{F}$ & $\begin{array}{l}\text { Co-curator of exhibitions for the V\&A } \\
\text { and other museums }\end{array}$ \\
\hline FG1 & Focus group participant & $\mathrm{F}$ & $\begin{array}{l}\text { Employee for a Packaging Firm } \\
\text { supplying Fashion Brands }\end{array}$ \\
\hline FG2 & Focus group participant & $\mathrm{M}$ & $\begin{array}{l}\text { Master student of Automation } \\
\text { Engineering }\end{array}$ \\
\hline FG3 & Focus group participant & $\mathrm{M}$ & Owner of a firm of Industrial Supply \\
\hline FG4 & Focus group participant & $\mathrm{M}$ & Employee for a firm of Mould Design \\
\hline FG5 & Focus group participant & $\mathrm{M}$ & $\begin{array}{l}\text { Area Manager in a Telecommunication } \\
\text { Firm }\end{array}$ \\
\hline P1 & Fondazione Prada insight & $\mathrm{M}$ & Manager in Fondazione Prada \\
\hline P2 & Fondazione Prada insight & $\mathrm{F}$ & Curator in Fondazione Prada \\
\hline
\end{tabular}

Table 1 - Research participants' contribution and role description. 